П. П. Дашинимаева. Принцип единства дескрипции и прескрипции в описании монгольских языков РФ

Научная статья

УДК 821.512

DOI: $10.18101 / 2305-459 X-2020-4-47-52$

\title{
ПРИНЦИП ЕДИНСТВА ДЕСКРИПЦИИ И ПРЕСКРИПЦИИ В ОПИСАНИИ МОНГОЛЬСКИХ ЯЗЫКОВ РФ
}

\author{
(C) Дашинимаева Полина Пурбуевна \\ доктор филологических наук, профессор, \\ Бурятский государственный университет имени Доржи Банзарова \\ Россия, 670000, г. Улан-Удэ, ул. Ранжурова, 6 \\ pdash@bsu.ru
}

Аннотация. В статье поднимается проблема методологии исследования регионального языка современной России на примере бурятского. Автор настаивает на том, что формально-лингвистический дескриптивный подход изжил себя, поскольку дает описание некой идеальной системы, которая более не функционирует в этом виде. Другой причиной его нерелевантности является несоответствие системному полидисциплинарному видению объекта исследования. Автор предлагает обратиться к прескриптивному подходу в рамках нового направления эколингвистики, т. к. в недрах этой области языковедения начинают разрабатываться модели причинно-следственных связей, соединяющих внешние и внутренние условия формирования и развития языковой ситуации в регионе. В качестве возврата витальности языка монгольский может определяться в качестве исходного языка в широком и узком смыслах. Также предлагается разрабатывать прескрипции в ряде других предметных областей - лингвистическом ландшафте, лексикографии.

Ключевые слова: дескрипция и прескрипция; методология; эколингвистика; бурятский и монгольский языки; внешний и внутренний.

\section{Для цитирования}

Дашинимаева П. П. Принцип единства дескрипции и прескрипции в описании монгольских языков РФ // Вестник Бурятского государственного университета. Язык. Литература. Культура. 2020. Вып. 4. С. 47-52.

Когда заканчивается четверть столетия - период, определяющий смену поколений, наука должна подвергнуть методологической ревизии качество исследований на предмет его соответствия запросам нового поколения, которое выросло в новых парадигмах семейной, образовательной, социальной политики. Другими словами, в процессе их освоения у молодых формируются такие внутренние установки ментального и вербального поведения, которые в значительной мере отличаются от среднего и старшего поколений. Соответственно векторы современных научных парадигм знания должны взаимопересекаться во множестве предметных граней уже в других точках.

Как представляется, языковедение является именно той отраслью, которая не может не находиться на острие таких точек, поскольку человек разумный, эксплуатирующий язык/-и, не только добывает нужную информацию, вступая в коммуникацию в качестве homo loquens (человека говорящего), но и 
навязывает социуму свое убеждение как homo significans (человек обозначающий, создающий значения), порой ведя свои сложные коммуникативные игры (ср. воркаут площадка) как homo ludens (человек играющий). Соответственно, лингвистике следует не только описывать нормативный литературный язык со всем перечнем морфологических, синтаксических, лексико-стилистических формальных показателей (парадигма прошлого столетия), но и выявлять слабые и странные места их использования, которые представляют собой и естественную, и искусственно созданную динамику протекания речемышления, причины актуализации подобных речевых отклонений, состояние их функциональной стабильности, обусловливающей возможный переход в другой статус (даже около-стандартный), степень нанесения девиантных речевых тактик осознанного и неосознанного ущерба социуму и государственности (парадигма нынешнего столетия).

Второе можно рассматривать в рамках эколингвистики. Первая составляющая понятия - экология/экологичность - является предметом зарубежных исследований относительно языка-речи-мышления-коммуникации еще с 1960-х гг. как вскрытие негативного воздействия СМИ на сознание читателей. Здесь можно упомянуть вклад канадского ученого М. Маклуэна, который изящно показал эволюцию понимания степени воздействия медийных каналов в слоганах, включенных в названия своих работ 1964 и 1967 гг. - The medium is the message (Медиа - это сообщение) и The Medium Is the Massage (Медиа это массаж). Так, формально-технологическое (дескриптивное) описание средств СМИ через три года сменяется использованием прескриптивного ${ }^{1}$ (предписывающего) подхода - попыткой вскрыть манипулятивную, потому вредоносную, сущность медиаресурсов.

Не секрет, что в современной науке совокупное применение принципов дескрипции и прескрипции равнозначно стоит в одном ряду с другими принципами ведения исследования - релевантностью теоретических обобщений, необходимостью погружения объекта в дополнительные контексты, усиливающего степень доказательности и т. д. Как справедливо указывает Е. Куценко, «хорошая методология - это вовсе не та методология, которая реалистична, а та, которая позволяет построить на своей основе полезные с точки зрения практики теории. Многочисленные ветви и листья хорошей теории требуют плотного, монолитного ствола методологии» [6].

Для того чтобы показать важность применения новых лингвистических методологий, сначала приведем мысль онтологического толка Юрия Лотмана (здесь и далее выделения наши. - П. Д.):

...Сколь ни распространяли бы мы круг наших сведений, потребность в информации будет развиваться, обгоняя темп нашего научного прогресса. Следовательно, по мере роста знания незнание будет не уменьшаться, а возрастать, деятельность, становясь более эффективной, - не облегчаться, а

${ }^{1}$ Прескрипция (от лат. prescribere) - предписание, норма, высказывание, обязывающее, разрешающее или запрещающее что-то сделать и не являющееся истинным или ложным [https://dic.academic.ru/dic.nsf/enc_philosophy]. 
П. П. Дашинимаева. Принцип единства дескрипции и прескрипции в описании монгольских языков РФ

затрудняться. В этих условиях недостаток информации компенсируется ее стереоскопичностью - возможностью получить совершенно иную проекцию той жее реальности, перевод ее на совершенно другой язык. Польза партнера по коммуникации заключается в том, что он другой... [7, с. 45].

Попробуем трансформировать идею автора относительно вскрытия потенциала прескриптивного подхода в описании функционирования современных монгольских языков, в частности бурятского:

...Сколь ни распространяли бы мы круг наших сведений о морфологии, синтаксисе, лексическом и стилистическом разнообразии потенцииала бурятского языка, потребность в другой информации будет развиваться. Следовательно, по мере роста статического знания незнание стремительно изменяющегося мира и способов его познания через призму языка-культуры будет не уменьшаться, а возрастать, а речевая деятельность в связи с этим - не облегчаться, а затрудняться. В этих условиях недостаток информации компенсируется возможностью получить совершенно иную проекцию той же реальности, перевод ее на совершенно другой научный язык. Описать жизнь языка более полно, чем описание внешних его атрибутов, - значит учесть эти изменения в видении и вербализации объектов, их признаков, отношений между объектами, представляющих для современника иной интерес, чем раньше.

Рассмотрим в первом приближении, какие траектории исследования возможны как попытки видоизменить традиционную методологию.

1. Прескриптивный подход не значит, что можно идти только в векторе «от теории к практике», т. е. иллюстрированием некоей идеальной теории примерами применения в языке. Можно идти от материала, данного в дескриптивных словарях, где представлено описание лексики с фиксацией всех имеющихся употреблений, в том чиле диалектных форм, просторечий, сленга, жаргонизмов - менее стандартных явлений. При этом то, что неустойчивые (в плане нормы) употребления слов и структур не являются объектом языковой политики государства [5], подтверждает близорукость видения, ведущую к следующему причинно-следственному положению дел: поскольку есть установка собирать литературный лексикон, постольку обходимы вниманием языковые ненормативности, соответственно, отсутствует проблема их дальнейшего описания, выяснения отношения к ним в рамках языковой политики в виде прескрипций разного рода (в области дидактики, психологии, социологии и т. д.). Логично, что авторы базового словаря бурятского языка (Буряад-ород толи, Л. Д. Шагдаров, К. М. Черемисов, 2008) не ставили задачу включать нестандартную, инвективную лексику, тем не менее в словнике изредка встречаются лексемы, относящиеся к этим разрядам, которые сопровождаются примечаниями «устаревшее», «бранное»: хаатарщан 'усm. каторжник', боохолдой 'бран. чёрт'.

2. Тем более в словаре не фиксируются иллюстрации бикодового дискурса и отсутствует системное описание явления в рамках прескриптивных технологий. Напомним читателям, в чем заключается их структурная природа на примере бурятско-русского дискурса (в нижепредставленных иллюстрациях выделены русские лексические форманты): 
Аварида орожо, хорошо амиды гарааш... эдэи знаагууд... юумэ подсказывайжа байна. 'Попав в аварию, хорошо, живой остался... Это знаки... они подсказывают что-то.'

Вообщеэ энэи юумэ үзөөгүй же. 'Вообще-то он не подвергался же никаким испьттаниям.'

Несколько замечаний онтологического порядка к подобного рода девиантным дискурсам. Автоматически (неосознанно) запускаемая в когнитивном пространстве homo loquens речь со смешением кодов контактирующих языков является результатом самоорганизации языковой системы исходного языка (типа, эксплуатирую то, что есть, недостающее беру из рядом лежащего когнитивного инвентаря), которая ориентируется на метаописание (обобщенные правила языка вообще). В процессе восприятия самим homo significans данный комплекс с внешней точки зрения представляется как некоторое естественное речевое единство, так же со стороны воспринимающего он не видится как результат креативного воображения в статусе homo ludens, да и с точки зрения психологии коммуникации на уровне социума уже не создается ощущение девиантности речевого поведения. Это означает, что имеет место далеко идущая креолизация региональных языков: разум билингва смирился с тем, что помимо воли один из его языков навязывает свои правила и ограничения на другой, несмотря на совершенно различную природу грамматик. Бурят-билингв воспринимает свой язык сквозь призму метаописаний, потому что он не в силах в спонтанной речи осознанно скреплять и нанизывать слова в соответствии с конкретными - чисто бурятскими - правилами. Когнитивная суть этого явления лежит в нейрофизиологии речемыслительной деятельности.

3. Эколингвистическое исследование можно выполнять в рамках определения лингвистического ландшафта региона - картины представленности языков и их соотношений в общественных пространствах во всех видах надписей, вывесок и уличных реклам. Мы, граждане, населяющие эту территорию, являемся их потребителями, даже если не вчитываемся и не анализируем их явное или скрытое донесение осознанно, поскольку обработка увиденного не обязательно происходит под прямым контролем.

Согласно Г. С. Доржиевой, А. О. Ткачевой (2020), из эргонимов г. УланУдэ наименования на бурятском языке составляют только 14,5\% (напр. Алтан гэрэл 'Золотой луч', Буузын гэр 'Дом (для) буз', Ээжийн хоол 'Угощения матери'), гибридные - 11\% (напр. ШашлькоFF, Бууза Room, Metiss bar, Цуйван Баирович). Основаниями столь маленького соотношения бурятского языка в ландшафте города авторы логично объясняют «апелляцией к фоновым знаниям представителей бурятского этноса, ставшим общими для лиц других национальностей, проживающих в Республике Бурятия» [5, с. 61]. Однако, учитывая функциональную слабость языка, с одной стороны, психонейрофизиологию восприятия объектов внешнего мира, обусловливающую формирование внутреннего содержания потребителей, в том числе ценностных ориентиров, - с другой, ученые могли бы создать эколингвистический портрет Улан-Удэ и для развития самой науки в этом направлении, и для соответствующего воздействия 
П. П. Дашинимаева. Принцип единства дескрипции и прескрипции в описании монгольских языков РФ

на государственные и муниципальные структуры, занимающиеся языковой ситуацией в регионах.

4. В рамках прескриптивного подхода к изучению проблемы достижения баланса языков эффективным методом видится постановка именно монгольского языка во главу угла на многих уровнях теоретико-прикладной деятельности. Так, в широком смысле монгольский мог бы браться в качестве иностранного языка для обратного прихода к бурятскому/калмыцкому, в узком смысле - по меньшей мере лексикографическим ресурсом внедрения новых слов в терминологию современных отраслей знания по некоей аналогии, учитывая разницу правил фонологической и грамматической систем. Представим интересные термины из языкознания:

- авианы харилцан уялдаа (фонологическая корреляция)

- магад шэнж (потенциальность + вероятность)

- логикийн чиглэл (логический подход/направление)

- таамаглал (гипотеза, предположение)

- түүхэн харьцуулсан хэл зуй (сопоставительная грамматика в диахронии) [4].

5. В основе обсуждаемого подхода, как ранее отмечено, должно находиться системное понимание взаимокорреляции внешних и внутренних условий, сформировавших положение дел с региональным языком.

Семиосфера монгольского (в том числе бурятского, калмыцкого, халха, хамниганского) языка - полидисциплинарное пространство исследования, формируемое из представлений современных проблем функционирования языка с точки зрения разных наук - психологии в дискурсивном, культурологическом аспектах, биологии языка, нейрофизиологии естественного семиозиса, лингвистики в социальном, политическом и юридическом аспектах. Так, отправляясь в научный путь в рамках учета данной полидисциплинарности объекта, исходными пунктами современной методологии изучения языка выступают по меньшей мере следующие вопросы:

Что есть, что осталось в современном языке относительно той идеальной системы, которая описана в словарях и письменных текстах? Какие нововведения в современный вокабуляр следует внести и в дальнейшем кодифицировать для удовлетворения информационной потребности? Какие другие шаги рекомендуется сделать на региональном, муниципальном, корпоративном уровнях для удовлетворения энергетической потребности? Какие меры трансляции языка в пространстве и времени будут обеспечивать ежедневный 6-часовой баланс каждого языка для удовлетворения производственной потребности регионального языка? Какие привычки, убеждения, взгляды следует видоизменить для обеспечения перехода декларативности правовых документов в сторону их операциональности соответственно для возмещения потребности в безопасности языка? [4] Отказ от традиционного подхода описания языка с точки зрения только формальных признаков в сторону системных исследований по безопасности жизнедеятельности языка, (ре)брендированию регионального языка-культуры с целью возвращения статуса его витальности требует научно обоснованных рекомендаций, учитывающих механизм взаимообусловленности внешних и внутренних факторов, приведших к креолизации монгольских языков на территории РФ. 
Словари

1. Шагдаров Л. Д., Черемисов К. М. Буряад-ород толи. Бурятско-русский словарь: в 2 т. Улан-Удэ: Респ. Тип., 2006-2008. Т. 1. 636 с. Т. 2.707 с.

2. Төмөртогоо Д., Бат-Ирээдүй Ж. Хэл шинжлэлийн монгол-англи толь бичиг. Улаанбаатар: МУИС Пресс хэвлэлийн газар, 2016. 424 х.

Лuтература $360 \mathrm{c}$.

3. Баранов А. Н. Введение в прикладную лингвистику. М.: Едиториал УРСС, 2003.

4. Семиосфера бурятского языка. Дескрипция и прескрипция: монография / П. П. Дашинимаева [и др.]. Улан-Удэ : Изд-во Бурят. гос. ун-та, 2018. 196 с.

5. Доржиева Г. С., Ткачева А. О. Функции эргонимов в туристической индустрии Республики Бурятия // Вестник СВФУ. 2020. № 3(77). С. 60-73.

6. Куценко Е. Блеск и нищета методологий. URL: https://evg-ko.livejournal.com/11525.html (дата обращения 17.09.2020).

7. Лотман Ю. М. Феномен культуры // Избранные статьи: в 3 т. Т. 1. Статьи по семиотике и топологии культуры. Таллин: Александра, 1992. С. 34-45.

\section{DESCRIPTION AND PRESCRIPTION CO-REALIZATION PRINCIPLE: MONGOLIAN LANGUAGES IN RUSSIA}

\section{(C) Polina P. Dashinimaeva}

Science Doctor in Philology, Professor at the Department of Translation and Intercultural Communication, Institute of Philology, Foreign Languages and Mass Communications

Banzarov Buryat State University

6, Ranzhurova Str., Ulan-Ude, 670000, Russian Federation

pdash@bsu.ru

Absrtact. The paper focuses on the problem of linguistic methodology, namely in research of the RF regional languages, including Buryat. The author claims that the form-oriented descriptive approach has been out-of-date, since it depicts a certain ideal system that no longer functions or manifests in the given way. Another reason for its irrelevance is the inconsistency with the system-like polydisciplinary vision of the object. The author suggests scholars' turning to the prescriptive approach in the framework of the new ecolinguistic trend, since the latter tries to model cause-and-effect relationships, the ones that connect external and internal conditions to have the language situation in the region formed. In the issue of the language vitality reset, Mongolian might be referred as a source language in broad and narrow senses. There is also a need to develop prescriptions in linguistic landscape, and lexicography.

Keywords: description and prescription, methodology, ecolinguistics, Buryat and Mongolian languages, external and internal

Статья поступила в редакиию 18.11.2020; одобрена после рецензирования 24.11.2020; принята к публикации 24.12.2020. 